\title{
Leyes reguladoras de la prueba: de la soberanía judicial al control deferente de la Corte Suprema
}

\author{
Jorge Larroucau Torres*
}

\begin{abstract}
RESUMEN
La Corte Suprema debe controlar la correcta aplicación de las leyes reguladoras de la prueba, incluso cuando lo que se discute es la manera en que el juez valoró los datos disponibles. Este artículo demuestra que la reticencia a ejercer ese control responde a la concepción tradicional de la casación que ha fomentado la tesis de la soberanía judicial (tanto en su versión fuerte como débil). Dicho recelo se morigeró - vía casación en la forma-gracias al control de las motivaciones defectuosas, aunque la normatividad de las leyes reguladoras sugiere no limitar el control a este único supuesto; así lo demuestra la jurisprudencia, por ejemplo, en los casos de filiación y de acciones reales. Con todo, este control debe ser deferente con lo resuelto por el juez de instancia, ya que el diseño institucional de los procesos contempla otras formas de corregir los errores judiciales, evitando al mismo tiempo los riesgos de un control formalista y de uno vulgarizador.
\end{abstract}

Leyes reguladoras de la prueba - soberanía judicial - Corte Suprema

\section{Evidence law: From judicial sovereignty to respectful control by Supreme Court}

\begin{abstract}
The Supreme Court must control the correct application of Evidence Law, incluiding when discusion is about judicial assessment of evidence. This paper show that reluctance on the part of the Supreme Court to exercise that control comes of the traditional conception of cassation, wich has fostered the thesis of judicial sovereignty (in their strong and weak versions). This suspitions decrease-through formal cassation - due to the control of defective motivations, but the normative sense of Evidence Law suggest not limit control to this only situation; this is what the veredicts indicate, for example, in paternity suits and actions in rem. Anyway, this control must be respectful with judge since the institutional design of the judicial process includes others measures to correct judicial errors, avoiding at the same time the risks of formalistic and excessive control.
\end{abstract}

Evidence law - judicial sovereignty - Supreme Court

* Licenciado en Ciencias Jurídicas y Sociales, Universidad de Concepción. Doctor en Derecho, Universidad de Chile. Profesor de Derecho Procesal Civil, Pontificia Universidad Católica de Valparaíso, jorge.larroucau@pucv.cl.

Este artículo es parte de un proyecto financiado por un Fondecyt Regular ( $\mathrm{N}^{\circ} 1140986$ : "Conceptos fundamentales del derecho probatorio en Chile", 2014-2016) del que el autor es un investigador asociado.

Todas las reglas citadas corresponden al Código de Procedimiento Civil chileno de 1903 (= CPC) a menos que se indique lo contrario.

Artículo recibido el 25 de mayo de 2016 y aceptado para su publicación el 1 de marzo de 2017. 


\section{Corte Suprema y hechos}

E n 1989, Daniel Peñailillo sostuvo que si "la Corte Suprema acoge un recurso de casación en el fondo por infracción a las llamadas leyes reguladoras de la prueba, puede darse la notable situación de que resulten, como consecuencia, modificados los hechos"1. En 2002, Enrique Paillás agregó que en un sistema de sana crítica "jamás podría existir un recurso de casación [pues] la valoración de la prueba escapa al control del tribunal de casación" 2 . Y, en 2014, Javier Maturana sentenció que "con la muerte del recurso de casación en el fondo también desaparecerá la discusión sobre si las reglas de la sana crítica son normas reguladoras de la prueba"3.

Las premisas detrás de estas afirmaciones y de otras similares que existen en la literatura chilena provienen, en general, (i) de una cierta imagen acerca del rol que debe cumplir la Corte Suprema a la hora de controlar los fallos judiciales y, en particular, (ii) del recurso de casación como herramienta para ejercer dicho control, así como (iii) de una determinada concepción acerca de las reglas de prueba que enfatiza la prudencia y las creencias judiciales, a veces de un modo radical. En este artículo se aborda fundamentalmente esta última dimensión del problema, de modo que su objetivo no es discutir acerca de los límites de la casación o de la (in)conveniencia de una tercera instancia judicial ${ }^{4}$. El propósito es dar cuenta de una evolución en el modo en que la Corte Suprema ha concebido las leyes reguladoras de la prueba, transición que puede resumirse mediante las tesis de la soberanía judicial y del control deferente.

Para dar cuenta de este cambio se procederá del siguiente modo: (i) Primero se introduce la noción de leyes reguladoras de la prueba como un estatuto probatorio, distinguiendo en él dos versiones - una fuerte y otra débil-, para luego identificar cuatro pretextos -en un listado que no es exhaustivo- esgrimidos habitualmente por la Corte Suprema para excusarse de controlar el juicio de hecho. En segundo lugar, (ii) se muestra mediante un par de casos relevantes - la filiación y las acciones reales- que la decisión de controlar el juicio de hecho no siempre ha provenido del Poder Legislativo, sino que también ha sido tomada por la propia Corte Suprema con las actuales reglas de prueba existentes. Por último, (iii) se afirma que la normatividad de las leyes reguladoras de la prueba exige avanzar desde un control mínimo -y acotado a la motivación defectuosadel juicio de hecho hacia un control deferente por parte de la Corte Suprema, que evite

${ }^{1}$ Peñailillo, D., La prueba en materia sustantiva civil. Parte general, Editorial Jurídica de Chile, Santiago, 1989 , p. 13.

${ }^{2}$ Paillás, E., Estudios de derecho probatorio, Editorial Jurídica de Chile, Santiago, 2a ed. actualizada, 2002, p. 115.

${ }^{3}$ Maturana, J., Sana crítica. Un sistema de valoración racional de la prueba, Thomson Reuters, Santiago de Chile, 2014, pp. 461-462.

${ }^{4}$ Para un completo análisis del recurso de casación en Chile, Marín, J. C., "Proceso civil", en Revista de Derecho de la Universidad Adolfo Ibáñez, No 4, 2016, pp. 315 ss.; Marín, J. C., "Proceso civil. Los orígenes de la casación nacional. La casación en la jurisprudencia de 2005”, en Revista de Derecho de la Universidad Adolfo Ibánez, No 3, 2013, pp. 165 ss. 
tanto el riesgo del formalismo como el del vulgarismo en la corrección de los errores judiciales.

Ahora bien, aunque la posibilidad de controlar un fallo judicial basado en cómo se valoró la prueba ha sido históricamente una de las cuestiones más polémicas en el ámbito comparado, ello ha estado fuera de discusión cuando se trata de un modelo de doble instancia. Como lo notara Mirjan Damaška, en The Faces of Justice, "al contrario de lo que se dice a menudo, incluso hoy la 'libre evaluación de las pruebas' continental no es realmente libre: como conviene al proceso jerárquico, se pide a los jueces de primera instancia que justifiquen sus indagaciones, y sus razonamientos son escrutados por los tribunales de apelación. Claramente, si las indagaciones no hubiesen de observar formas regulares, las apelaciones por 'errores de hecho' estarían desprovistas de toda base"

En Chile, las "formas regulares" de la prueba que mencionara Damaška han recibido el nombre de leyes reguladoras de la prueba. Como se verá a continuación, dichas leyes no solo justifican que las Cortes de Apelaciones puedan revisar los hechos sino que también sirven de fundamento para que la Corte Suprema lo haga, incluso cuando se trata de la valoración de la prueba, sin limitar su intervención -como ha ocurrido en las últimas décadas- a la hipótesis de la motivación defectuosa mediante la disciplina de la casación en la forma. La explicación tradicional de quienes se han ocupado del nexo entre casación y prueba ha sido escéptica respecto de este control, señalando que "hasta que no se pase en todo o en parte del modelo de casación al de tercera instancia, control de hecho significa exclusivamente control sobre la motivación relativa al juicio de hecho"6. Pero es preciso notar que esta es una explicación que siempre enfatiza el medio empleado para llegar a la Corte Suprema -el recurso de casación- y deja en segundo plano el motivo por el que se plantea la discusión -las "formas regulares" de la prueba-. En lo que sigue, como se anticipó, el enfoque estará puesto en este segundo aspecto.

El límite para la Corte Suprema es recabar más información para decidir lo ocurrido ${ }^{7}$, pero a causa de que las leyes reguladoras de la prueba son efectivamente "leyes", su control no se agota en el supuesto de las motivaciones defectuosas. Estas leyes reguladoras, como lo dejó entrever el ministro Sergio Muñoz, no son pura expresión de soberanía judicial $^{8}$, que ha sido la noción tradicionalmente empleada por los propios tribunales para no dar lugar a este control.

${ }^{5}$ Damaška, M., Las caras de la justicia y el poder del Estado. Análisis comparado del proceso legal, traducción de Andrea Morales, Editorial Jurídica de Chile, Santiago, 2000 (1986), p. 99.

${ }^{6}$ Taruffo, M., El vértice ambiguo. Ensayos sobre la Casación civil, traducción de Juan Monroy Palacios y Juan Monroy Gálvez, Palestra Editores, Lima, 2005 (1991), p. 179.

${ }^{7}$ Art. 807 inciso $1^{\circ}$ CPC: "En el recurso de casación en el fondo, no se podrán admitir ni decretar de oficio para mejor proveer pruebas de ninguna clase que tiendan a establecer o esclarecer los hechos controvertidos en el juicio en que haya recaído la sentencia recurrida".

${ }^{8}$ Muñoz, S., "Presente y futuro de la casación civil en Chile", en Derecho procesal contemporáneo. Ponencias de las XXII Jornadas Iberoamericanas de Derecho procesal, Raúl Tavolari coordinador, Editorial Jurídica de Chile, Santiago, T. I, 2010, p. 149: "La definición conceptual de las leyes reguladoras por parte de la jurisprudencia [...] deja de manifiesto el propósito que pretenden conseguir con su aplicación, esto es un correcto juzgamiento, noción que está asociada al mérito y este a los hechos y al derecho". 


\section{La tesis clásica de la soberanía judicial}

La jurisprudencia chilena asume que las leyes reguladoras de la prueba son un estatuto normativo del juicio de hecho en los procesos judiciales. Esta regulación incluye "deberes", "obligaciones"10, "limitaciones" y "prohibiciones" para el juez, de modo que si este no aplica tales leyes en un caso concreto expone su fallo a "la censura de la Corte de Casación" 11 .

De acuerdo con la Corte Suprema, como es bien sabido, estas leyes tienen un amplio campo de aplicación, ya que incluyen: “1) a aquellas normas que instituyen los medios de prueba que pueden utilizarse para demostrar los hechos en un proceso; 2) las que precisan la oportunidad en que pueden valerse de ellos; 3) las que se refieren al procedimiento que las partes y el juez deben utilizar para ofrecer, aceptar y aportar las probanzas al juicio; 4) a aquellas reglas que asignan el valor probatorio que tiene cada uno de los medios individualmente considerados y 5) a las que disciplinan la forma como el sentenciador debe realizar la ponderación comparativa entre los medios de la misma especie y entre todos los reconocidos por el ordenamiento legal"12. O sea, como lo consigna el $\mathrm{N}^{\circ} 5$ de este considerando, la valoración de la prueba forma parte de esta regulación en lo que dice relación con los preceptos que "disciplinan la forma como el sentenciador debe realizar la ponderación comparativa" de los datos disponibles; ello hace, por ejemplo, que el art. 428 CPC sea una ley reguladora de la prueba ${ }^{13}$.

\section{a. La tesis fuerte del no control}

Por alguna razón que valdría la pena indagar, una parte de la práctica judicial entendió que esta regulación de la prueba no mermaba en ningún sentido la soberanía judicial. Esta tesis puede ilustrarse mediante dos trabajos publicados por jueces que, al mismo tiempo, impartieron durante varias décadas clases de Derecho Procesal, en la Universidad de Valparaíso y en la Universidad de Chile, respectivamente.

En 1954, Carlos Anabalón señaló que estas leyes "no son fórmulas rígidas, precisas ni concretas, que puedan adaptarse a cada caso particular y dentro de las cuales se hayan de ver los jueces como aprisionados en un corselete de hierro; más bien son meras indicaciones para que estos se dirijan con mayor comodidad y confianza por el camino de la verdad en la apreciación de la prueba”. De acuerdo con Anabalón, se trataría de una

${ }^{9}$ Por todas: C. S., 3 enero 1966, Revista de Derecho y Jurisprudencia, T. LXIII, sec. $1^{\text {a }}$, citada en Salgado, L., La prueba: Objeto, carga y apreciación. Comentarios de jurisprudencia, Editorial Jurídica de Chile, Santiago, 1979, p. 102.

${ }^{10}$ Por todas: Rabie con Home Medical Clinic Chile S. A. (Help) y Veiga, C. S., 24 abril 2007, Rol No 38862005, vLex: 332775406, cons. $4^{\circ}$ (redacción de la ministra Margarita Herreros).

${ }^{11}$ Salgado (n. 9), p. 103.

12 Por todas: Sociedad Pesquera Entre Islas Limitada con Gatica, C. S., 5 abril 2012, Rol N 11746-2011, cons. $6^{\circ}$, LegalPublishing CL/JUR/773/2012 (Primera Sala: redacción del ministro Nibaldo Segura).

${ }^{13}$ Art. 428 CPC: "Entre dos o más pruebas contradictorias, y a falta de ley que resuelva el conflicto, los tribunales preferirán la que crean más conforme con la verdad”. 
"elasticidad -si así se pudiera decir-que la ley consagra en favor de los jueces para que estos apliquen el cartabón de su mente y de su conciencia" ${ }^{4}$.

En 2008, por su parte, Enrique Paillás reiteró algo que ya había aseverado en $2002^{15}$, en cuanto a que "las reglas sobre aparente prueba tasada que da el Código de Procedimiento Civil están tácitamente derogadas. La única regla vigente es el inciso $2^{\circ}$ del art. 426: Una sola presunción puede constituir plena prueba cuando, a juicio del tribunal, tenga caracteres de gravedad y precisión suficientes para formar su convencimiento" 16 .

Esta tesis fuerte de la soberanía judicial, en donde las leyes reguladoras son "meras indicaciones", o bien, "están tácitamente derogadas" (salvo la que se refiere a la presunción judicial), fue siempre minoritaria. La jurisprudencia, en su mayoría, se inclinó por una concepción débil de la misma.

\section{b. La tesis débil del no control}

Bajo una tesis menos fuerte, las leyes reguladoras de la prueba sí restringen la soberanía judicial. La Corte Suprema ha suscrito esta lectura al reconocer que el Poder Legislativo tomó una "decisión política básica y fundamental en cuanto al sistema probatorio, el procedimiento y la ponderación” con estas leyes, de modo que ajustarse a ellas "es una obligación de los magistrados" y, por esta razón, "su transgresión trae aparejada una sanción, cual es su ineficacia, la que se declara mediante una acción de nulidad" (Sociedad Pesquera Entre Islas Limitada con Gatica, cons. 6º).

El punto relevante es que, según la misma Corte Suprema, solo algunas de estas leyes son "esenciales respecto de la actividad probatoria", de modo que permiten "la intervención del Tribunal de Casación”. Según este punto de vista, los escenarios "esenciales” de la prueba se dan: "a) al aceptar un medio probatorio que la ley prohíbe absolutamente o respecto de la materia de que se trata; b) por el contrario, al rechazar un medio que la ley acepta; c) al alterar el onus probandi o peso de la prueba, en quien queda radicada la carga de aportar los elementos que acreditan los hechos que conforman la litis; d) al reconocer a un medio de prueba un valor distinto que el asignado expresamente por el legislador o hacerlo sin que se cumplan los supuestos objetivamente determinados por el legislador; e) igualmente, a la inversa, al desconocer el valor que el legislador asigna perentoriamente a un elemento de prueba, cuando este cumple efectivamente los supuestos legales, y f) al alterar el orden de precedencia en que deben ser llamados los medios probatorios y que la ley les asignare, en su caso" (Sociedad Pesquera Entre Islas Limitada con Gatica, cons. $\left.6^{\circ}\right)^{17}$.

14 Anabalón, C., El juicio ordinario de mayor cuantía, Editorial Jurídica de Chile, Santiago, 1954, pp. 259-260.

${ }^{15}$ Paillás (n. 2), pp. 114-115.

16 Paillás, E., El recurso de casación en materia civil. Derecho chileno y comparado, Editorial Jurídica de Chile, Santiago, 2008, p. 98.

${ }^{17}$ Por ejemplo, si un juez modifica la carga de la prueba en razón de la disponibilidad o de la facilidad probatoria -existiendo una regla legal que lo autorice a ello- y luego se desdice, volviendo al reparto original, 
Como se puede observar, la tesis débil excluye del control de la casación a "la ponderación comparativa de una misma clase de medio probatorio o de la apreciación que se realiza en conjunto de todos los medios", a pesar de que la Corte Suprema ha reconocido, como se mostró antes, que las reglas que "disciplinan la forma cómo el sentenciador debe realizar la ponderación comparativa” son leyes reguladoras de la prueba. De acuerdo con esta tesis débil, "la actividad jurisdiccional considera un componente básico de prudencia en la decisión", por lo que el juez tiene "libertad en la justipreciación [sic] de los diversos elementos probatorios"18. En otras palabras, "los jueces del fondo son soberanos para apreciar las pruebas" 19 .

\section{Excusas}

Quizás ha sido esta ambigüedad de la Corte Suprema, en cuanto a reconocer en algunos casos y negar en otras ocasiones que las reglas que "disciplinan la forma" de valoración sean leyes reguladoras de la prueba, lo que ha mantenido vigentes las dudas en cuanto a si ella puede ser controlada por dicho tribunal. En la práctica es más o menos usual que los litigantes insistan en que la Corte Suprema revise un fallo por la forma en que se valoró la prueba. Lo interesante del caso es que, para no acometer ese control, este tribunal no se limita a señalar que es incompetente en asunto de prueba, sino que se empeña en esgrimir -con bastante discrecionalidad- un repertorio de excusas específicas para la valoración de la prueba, siendo la más interesante de ellas la que reduce a las leyes reguladoras a un estatuto de reglas imperativas.

\section{a. Normas potestativas}

El caso típico en que la Corte Suprema aplica esta excusa es el del valor de la declaración de dos o más testigos, porque considera que la regla en juego (art. $384 \mathrm{~N}^{\circ} 2$ $\mathrm{CPC})^{20}$ no es una ley reguladora de la prueba ( = "ya que la demostración del hecho, al emplear la ley la palabra "podrá", queda entregada a la apreciación soberana de los jueces de la instancia”) ${ }^{21}$. La premisa aquí es clara, y doble: (i) por un lado, solo son

ello "podría tener trascendencia casacional”, Del Río, C., "Motivo de casación en el fondo civil en Chile: Problemas y perspectivas de reforma”, en Ius et Praxis, Universidad de Talca, Vol. 21, N 2, 2015, p. 193.

18 Por todas: Sepúlveda con Servicio de Salud Maule, C. S., 9 enero 2013, Rol No 2004-2010, cons. $4^{\circ}$ (Tercera Sala: redacción del ministro Pedro Pierry).

19 Por todas: Agrícola Industrial y Comercial Artificio de Pedegua S. A. con Sociedad Agrícola El Sauce Ltda., C. S., 10 enero 2013, Rol N 5026-2012, cons. $9^{\circ}$ LegalPublishing CL/JUR/70/2013 (Primera Sala: redacción del ministro Alfredo Pfeffer).

${ }^{20}$ Art. $384 \mathrm{~N}^{\circ} 2$ CPC: "Los tribunales apreciarán la fuerza probatoria de las declaraciones de los testigos conforme a las reglas siguientes: $2 \mathrm{a}$. La de dos o más testigos contestes en el hecho y en sus circunstancias esenciales, sin tacha, legalmente examinados y que den razón de sus dichos, podrá constituir prueba plena cuando no haya sido desvirtuada por otra prueba en contrario".

${ }^{21}$ Pincheira con Servicio de Salud Llanquibue, Chiloé y Palena, C. S., 25 mayo 2006, Rol No 6350-05, cons. $13^{\circ}$ (Tercera Sala: redacción del ministro Milton Juica). 
leyes reguladoras de la prueba las normas imperativas, no las potestativas y (ii), por otra parte, ninguna regla imperativa -salvo los casos de prueba tasada- ${ }^{22}$ invade el ámbito de la valoración de la prueba, cuyo ejercicio es siempre libre.

Acerca de esto último no es necesario detenerse en este lugar ${ }^{23}$. Lo que sí amerita una explicación de la propia Corte Suprema es la primera parte de su premisa, es decir, su categórica exclusión de las reglas potestativas del marco de las leyes reguladoras de la prueba, sobre todo porque ella misma ha dictado fallos en que incluye dentro de este estatuto probatorio a las reglas que "disciplinan la forma" de valorar las pruebas -las "formas regulatorias" aludidas por Damaška-. Así, por ejemplo y como lo enseña la experiencia chilena ${ }^{24}$, cuando en un caso de negligencia médica el juez no privilegia el testimonio de los especialistas que comparten la misma disciplina que el médico demandado, ¿dicha decisión sería ajena al Derecho probatorio y quedaría, por tanto, excluida del control de la Corte Suprema solo porque no existe una regla que le ordene al juez privilegiar esa clase de testimonios? Afirmar esto sería lo mismo que excluir del control de la Corte Suprema el fallo del juez que no acoge la acción de terminación del contrato de arrendamiento en que la cosa arrendada tiene un vicio que le impide parcialmente al arrendatario su goce, porque el Código Civil emplea en esta ocasión una regla potestativa: "el juez decidirá, según las circunstancias, si debe tener lugar la terminación del arrendamiento, o concederse una rebaja del precio o renta” (art. 1932 inciso $2^{\circ}$ ).

\section{b. Subjetividad}

Si la valoración de la prueba es entendida como una forma en que el juez se convence de la verdad o falsedad de los hechos y esa forma no expresa más que "un proceso intelectual interno y subjetivo, o sea, es materia de apreciación y por lo mismo de hecho,

${ }^{22}$ Por ejemplo, la Corte Suprema ha dicho que "es evidente que el aludido artículo 924 [del Código Civil] constituye una norma reguladora de la prueba, pues indica la forma en que se acredita la posesión de los derechos inscritos sobre inmuebles", Subiabre con Soto y otro, C. S., 5 agosto 2008, Rol No 4253-2007, cons. $4^{\circ}$, LegalPublishing CL/JUR/3102/2008 (Primera Sala: redacción del ministro Milton Juica).

${ }^{23}$ En la literatura especializada, por ejemplo, el trabajo de Alex Stein ha probado que las estrategias de exclusión, preferencia y corroboración que tienen lugar en un proceso judicial dan cuenta de formas de distribuir el riesgo de error, y que tal reparto no puede quedar entregado a las preferencias del juez. Por el contrario, lo que corresponde es implementar estas estrategias a todo nivel como estándares decisorios generales para el juez, de modo que el control sobre las evaluaciones que él hace del peso de la prueba, en contextos que están marcados por la incertidumbre, no solo sea una cuestión posible sino que también probable, Stein, A., "Contra la 'prueba libre", traducción de Jorge Larroucau Torres, en Revista de Derecho, Universidad Austral, Vol. 26, N 2, 2013 (1997), pp. 245 ss. Hock Lai Ho, por su parte, ha puesto de manifiesto que un juez que toma decisiones probatorias sobre la base de la prudencia debe apelar a criterios objetivos, como la gravedad y las consecuencias que supone para una persona el que un hecho sea tenido por cierto en su contra, para de ese modo justificar frente a las partes y ante la comunidad en general tales decisiones, Ho, H. L., A Philosophy of Evidence Law. Justice in the Search for Truth, Oxford Monographs on Criminal Law, Oxford University Press, 2008, pp. 213-229.

${ }^{24}$ Larroucau, J., “¿Cómo se prueba la responsabilidad civil médica en la justicia chilena?”, en Revista de Derecho, Universidad Austral, Vol. 27, No 2, 2014, pp. 46-48. 
que corresponde exclusivamente a los jueces del fondo" 25 , entonces la Corte Suprema tiene una nueva -y poderosa- excusa para no examinar la valoración de las pruebas. La razón para ello la hizo explícita Daniel Peñailillo: “como no es posible jerarquizar las conciencias en la misma forma en que están jerarquizados los tribunales, el sistema [de valoración de la prueba entendida como un asunto de persuasión moral] estorba la justificación de los recursos procesales. La revisión de los hechos no sería posible, pues el tribunal superior no podría arrogarse mayor o mejor conciencia que el inferior" 26.

La potencia de este subterfugio es tal que alcanza incluso a las Cortes de Apelaciones y neutraliza su capacidad para revisar los fallos en aspectos de hecho, al mismo tiempo que hace ineficaz cualquier sistema de recursos (apelación, nulidad, casación) que se implemente en la administración de justicia.

\section{c. Hecho y derecho}

Nuevamente los juicios por negligencia médica ofrecen un buen ejemplo para presentar otra excusa de la Corte Suprema. Este tribunal ha decidido no examinar un veredicto al señalar que "inferir la causalidad" ( = "inferir la negligencia” o "inferir la responsabilidad”) supone siempre una calificación jurídica, de manera tal que es una cuestión "de derecho" y no "de hecho", por lo que no es posible hablar de infracción a leyes reguladoras de la prueba.

Si bien esta distinción entre hecho y derecho es "la nota formal que caracteriza la casación y la distingue de una tercera instancia" 27 , el pretexto es criticable al menos por dos razones: (i) porque, tal como lo esgrime la Corte Suprema, rigidiza en demasía una distinción que es bastante más dúctil y funcional ${ }^{28}$; y (ii) porque con esto se ignora el

${ }^{25}$ Por todas: C. S., 1 de abril de 1974, Revista de Derecho y Jurisprudencia, T. 68, sec. $1^{\text {a }}$, p. 76 citada en Rioseco, E., La prueba ante la jurisprudencia. Derecho civil y procesal civil, Editorial Jurídica de Chile, Santiago,

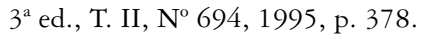

26 Peñailillo (n. 1), pp. 19 (nota 27), 25, 89-93.

27 Atria, F., "Proceso civil", en Revista de Derecho, Universidad Adolfo Ibáñez, No 2, 2004, p. 307.

${ }^{28}$ Esta crítica es extensible a lo dicho por Mario Mosquera y Cristián Maturana en cuanto a que sería la resolución que recibe la causa a prueba la que permitiría diferenciar claramente los aspectos de hecho (no controlables) de los de calificación jurídica (controlables), Mosquera, M. y Maturana, C., Los recursos procesales, Editorial Jurídica de Chile, Santiago, 2010, pp. 304-305. Si bien Mosquera y Maturana están en lo correcto al identificar a la resolución que recibe la causa a prueba como una pieza clave en el puzle del control de los hechos, lo que pasan por alto es que precisamente es en la resolución que recibe la causa a prueba donde la distinción entre hecho y derecho se difumina, debido a la simbiosis que la ley procesal chilena hizo entre thema decidendum (el asunto a decidir) y thema probandum (el asunto a probar) al ordenar que solo se reciba la causa a prueba por "hechos sustanciales controvertidos" (art. 318 inciso $1^{\circ} \mathrm{CPC}$ ). Enrique Paillás, en cambio, notó correctamente que "la circunstancia de que existe un derecho de la prueba que interviene en la comprobación de los hechos de la causa demuestra que el hecho y el derecho no son dos campos antagónicos e incomunicables, sino, por el contrario, dos planos superpuestos del proceso”, Paillás (n. 16), p. 62. En la literatura especializada en prueba, en tanto, Ronald Allen y Michael Pardo han demostrado que esta distinción entre hecho y derecho cumple un rol funcional a la carga de trabajo de jueces y jurado en el sistema judicial norteamericano, Allen, R. y Pardo, M., "The Myth of the Law-Fact Distinction", en Nortbwestern University Law Review, Vol. 97, N 4, 2003, p. 1770. 
sentido en que las leyes reguladoras dan cuenta de un estatuto normativo de la prueba, como la propia Corte Suprema lo ha reconocido al aludir a ellas como un conjunto de deberes, obligaciones, limitaciones y prohibiciones que los jueces deben respetar cuando juzgan los hechos 29 .

\section{d. Ordenatoria litis y decisoria litis}

La valoración de la prueba tampoco podría ser controlada porque sus reglas son ordenatoria litis y no decisoria litis. La Corte Suprema, por ejemplo, ha sostenido que el art. $341 \mathrm{CPC}$, que ni más ni menos enumera los medios de prueba admisibles en un juicio $^{30}$, sería una norma ordenatoria litis $^{31}$.

La situación de estas leyes, entonces, sería análoga a la de las reglas de interpretación, que "por sí mismas" no son vistas como decisoria litis por la Corte Suprema, de modo que tienen que relacionarse con otra regla para que proceda una casación en el fondo ${ }^{32}$.

\section{LA DECISIÓN DE CONTROLAR LA VALORACIÓN DE LA PRUEBA MEDIANTE LA CASACIÓN}

La tesis de la soberanía judicial, tanto en sus versiones fuerte y débil, con sus múltiples excusas para el caso de la valoración de la prueba, se alinea con la "ola abolicionista" del Derecho probatorio que fuera denunciada para los sistemas angloamericanos durante la segunda mitad del siglo $\mathrm{XX}^{33}$. La consecuencia de este fenómeno es que los asuntos de hecho quedaron solo en manos de los jueces y del sentido común, al margen de toda regla.

En esta segunda parte se muestra cómo esta tendencia ha sido corregida en la práctica chilena por decisiones que han provenido tanto del Poder Legislativo como de la propia Corte Suprema ${ }^{34}$. Para ello será útil considerar los casos de la filiación y

${ }^{29}$ Iván Hunter ha notado que esta tendencia en la práctica a no considerar a la prueba como una cuestión sustantiva ha servido para inhibir el debate en torno a ella en las instancias judiciales ("al tratarse de disposiciones que no permiten derivar efectos jurídicos sustantivos, las partes no realizan grandes esfuerzos en su aplicación, pues entienden además que se trata de normas que tiene que ser imperativamente aplicadas por los jueces"), Hunter, I., La aplicación judicial del derecho en el proceso civil. Doctrina, jurisprudencia y derecho comparado, Thomson Reuters, Santiago de Chile, 2015, p. 194.

${ }^{30}$ Art. 341 CPC: "Los medios de prueba de que puede hacerse uso en juicio son: Instrumentos; Testigos; Confesión de parte; Inspección personal del tribunal; Informes de peritos; y Presunciones”.

${ }^{31}$ Landeros con Painemal, C. S., 07 junio 2007, Rol No 6279-2005, cons. $6^{\circ}$ (Primera Sala: redacción del Ministro Juan Araya) citada en Zavala, J., Jurisprudencia del recurso de casación en el fondo y en la forma, Editorial PuntoLex, Santiago de Chile, 2007, p. 379.

${ }^{32}$ Romero, A., El recurso de casación en el fondo civil. Propuestas para la generación de precedentes judiciales, Thomson Reuters, Santiago de Chile, 2013, pp. 46-47.

33 Stein, A., "The Refoundation of Evidence Law", Canadian Journal of Law E Jurisprudence, 1996, Vol. 9, pp. 279-284.

${ }^{34}$ Es factible recordar que las leyes reguladoras de la prueba no se incluyeron en el Código de 1903 como una causal típica de la casación en el fondo porque se estimó que bastaba con la hipótesis general del 
de las acciones reales, debido a que en ellos se ha trastocado lo que tradicionalmente la jurisprudencia chilena había dicho acerca de la gravedad de una presunción judicial y la valoración de la prueba según la sana crítica; esto es, que dichos temas no podrían ser controlados por la Corte Suprema.

\section{a. La gravedad de una presunción}

La mejor evidencia disponible en los juicios de filiación es la prueba de ADN, aunque el peso de tal prueba no se encuentre prefigurado por la ley, sino que por una Resolución Exenta N ${ }^{0} 1450$ del año 2000, que da cuenta de las “consideraciones estadísticas” y las “conclusiones" del informe que elabora el Servicio Médico Legal. La reforma en 2005 a la regla que le permitía al juez presumir la filiación ante la negativa injustificada del demandado a practicarse el examen de ADN es un buen ejemplo de la voluntad de controlar la valoración de la prueba, al mudar una presunción judicial por una simplemente legal, haciendo con ello explícita la viabilidad del recurso de casación en el fondo ${ }^{35}$.

Antes de 2005, la Corte Suprema controlaba la valoración de la negativa injustificada del demandado mediante el recurso de casación en la forma, en dos de sus variantes: (i) indefensión, porque el examen de $\mathrm{ADN}$ hace posible el derecho de defensa de quien demanda la filiación, de modo que al no contar con esa prueba se pone en jaque un trámite o diligencia esencial del proceso (art. 768 No 9 CPC); y (ii) por una motivación defectuosa del juez al no presumir la filiación ante la negativa del demandado (art. 768 $\mathrm{N}^{\circ} 5$ CPC) $)^{36}$.

Después de 2005, en cambio, al crearse una norma imperativa -una presunción simplemente legal-, la Corte Suprema perdió la excusa de no controlar esta valoración también mediante la casación en el fondo, porque -según su propia tesis- debía reconocer en ella una ley reguladora de la prueba ${ }^{37}$. Lo relevante en este punto es que, antes

recurso ( = infracción de ley que influye en lo dispositivo del fallo), Romero, A., Aguirrezabal, M. y Baraona, J., "Revisión crítica de la causal fundante del recurso de casación en el fondo en materia civil", en Ius et Praxis, Vol. 14, No 1, 2008, p. 234.

${ }^{35}$ Larroucau, J., "Presunciones, negativa (in)justificada y prueba de ADN en la filiación”, en Revista de Derecho de Familia, Santiago de Chile, No 4, 2014, pp. 44-47.

${ }^{36}$ Por todas: González con Mobr, C. S., 30 octubre 2003, Rol No 145-2003, LegalPublishing No 28791, cons. $3^{\circ}$ (Primera Sala: redacción del ministro Eleodoro Ortiz): "El fallo recurrido no cumple con este requisito, toda vez que la Corte de Apelaciones, al revocar el fallo de primer grado y rechazar la demanda, omitió toda consideración y análisis sobre las razones por las cuales, en su concepto, la presunción legal del inciso $2^{\circ}$ del artículo 199 del Código Civil no es grave”. Carlos Díaz, aunque confundiendo a la sana crítica con la apreciación en conciencia, defendió tempranamente el control de la valoración de la prueba en la justicia de familia por la vía de la casación, López, C., "Apreciación de la prueba por la sana crítica y procedencia del recurso de casación en el fondo en los procesos ante los tribunales de familia”, en Gaceta Jurídica, No 294, 2004, p. 27.

${ }^{37}$ Las razones para legislar una presunción son varias, entre las que se pueden mencionar (i) la eficiencia (para evitar pérdida de tiempo y dinero si se trata de hechos que normalmente ocurren del modo en que se presume), (ii) la justicia (cuando se trata de hechos cuya prueba es muy difícil) y (iii) la equidad (cuando se trata de hechos cuya prueba está en manos de otra persona), Bohlen, F., "The Effect of Rebuttable 
de 2005, la Corte Suprema no solía emplear este pretexto, ya que aceptaba la casación en el fondo cuando un juez le negaba gravedad a la presunción de filiación en el caso de negativa injustificada al examen de $\mathrm{ADN}$, ya que la gravedad de tal presunción estaba dada por el antiguo art. 199 del Código Civil; o sea, reconocía en una parte de esa presunción judicial a una ley reguladora de la prueba ${ }^{38}$.

La historia reciente de los juicios de filiación sirve para ver cómo el Poder Legislativo reconoce por medio de una ley reguladora indubitada -al ser de origen legal e imperativa- una práctica judicial que ya se hacía cargo del control del juicio de hecho gracias a las diversas variantes de la casación: (i) en el fondo, cuando el juez no reconocía la gravedad de la presunción, y (ii) en la forma, ya sea por indefensión o porque el juez no había motivado lo suficiente su decisión en lo que se refería a la gravedad, precisión y concordancia de la presunción ${ }^{39}$.

\section{b. La valoración del peritaje según la sana crítica}

Lo que la soberanía judicial pretende lograr, es factible recordarlo una vez más, es impedir "que se lleve a cabo [una] nueva valoración de las probanzas [sic], distinta de la ya efectuada por los jueces del mérito" ${ }^{40}$. Pero, a pesar de esta contundente declaración, algunas veces, como es bien sabido, la Corte Suprema sí revisa "la ponderación comparativa” de la prueba hecha por el juez de instancia ${ }^{41}$. Por ejemplo, a raíz de una acción de demarcación y cerramiento la Corte Suprema casó de oficio la sentencia de segunda instancia por "prescindir de la cabal ponderación de la prueba rendida [y por]

Presumptions of Law upon the Burden of Proof', en University of Pennsylvania Law Review and American Law Register, Vol. 68, No 4, 1920, pp. 314-315.

${ }^{38}$ Por todas: Cardoza con Perotti, C. S., 6 julio 2005, Rol No 5616-2004, cons. $6^{\circ}$ (Primera Sala: redacción del abogado integrante Manuel Daniel): "La presunción que contiene la norma del artículo 199 inciso $2^{\circ}$ del Código Civil es de tal relevancia, que el legislador le ha atribuido los caracteres de 'gravedad', que el artículo 426 ya indicado, entregaba al análisis y ponderación de los jueces. Sobre el particular, y, teniendo presente la definición anterior y lo que señala el Diccionario de la Real Academia 'grave' es aquello 'de mucha entidad o importancia'; en consecuencia, cuando la ley califica y establece la gravedad de la presunción en comento, no puede sino concluirse que el legislador ha considerado que la única razón que podría tener una persona para negarse, sin justificación alguna a realizarse la prueba de ADN, es que efectivamente fuera el padre biológico y lo quisiera ocultar".

${ }^{39}$ La presunción judicial o presunción de hecho se entiende como "una deducción lógica de máximas de la experiencia, las cuales en virtud de su tipicidad, resultan adecuadas para la acreditación de hechos, y para cuya refutación se exigirá la contraprueba", Correa, C., "La presunción de hecho como figura jurídica en el derecho procesal civil alemán”, en Revista de Estudios de la Justicia, No 20, 2014, p. 117.

${ }^{40}$ Por todas: Barreda con Illia, C. S., 31 enero 2012, Rol No 3283-2011, cons. 13², LegalPublishing CL/ JUR/331/2012 (Primera Sala: redacción del ministro Juan Escobar). En 1991, Michele Taruffo ya denunciaba como uno de los riesgos más obvios de permitir el control de los hechos que "frente al juicio de hecho, el control de la Corte de Casación tiende a transformarse en un reexamen de la reconstrucción de los hechos y de la valoración de las pruebas", Taruffo (n. 6), p. 199.

${ }^{41}$ Larroucau, J., “Acciones reales y estándares de prueba”, en Ius et Praxis, Universidad de Talca, Vol. 21, No 2, 2015, pp. 147-149. 
carecer su sentencia de los razonamientos indispensables para fundar sus conclusiones y sustentar su determinación" 42 .

Esta propensión a casar de oficio en la forma configura, a estas alturas, una clara línea jurisprudencial de la Corte Suprema, incluso cuando se trata de un peritaje valorado según la sana crítica (arts. 775 y $768 \mathrm{~N}^{\circ} 5$ CPC) ${ }^{43}$. Solo a modo de ejemplos se pueden citar los siguientes casos: (i) la Corte Suprema casó un fallo de la Corte de Valdivia porque estimó como confesión a una declaración que en segunda instancia no se la evaluó como tal ${ }^{44}$; (ii) se casó de oficio un fallo de segunda instancia que confirmó el rechazo de la demanda, debido a que en él no se consideraron como pruebas del dominio del actor su inscripción conservatoria, la presunción legal de buena fe y una posesión regular del terreno de más de cinco años ${ }^{45}$; (iii) se casó de oficio porque un peritaje, aunque acompañado fuera de plazo, debió ser valorado, ya que así lo exige la buena fe procesal; ${ }^{46}$ y (iv) se ha casado de oficio cuando la Corte Suprema considera, a diferencia de las instancias judiciales, que el peritaje constituye una "completa prueba para convencer al tribunal que los demandados ocupan parte del predio de los actores" 47 .

La cuestión a dilucidar, entonces, es si este control que la Corte Suprema ha instalado mediante la casación en la forma, en juicios como los de filiación y de acciones reales, puede promoverse también por medio de la casación en el fondo ${ }^{48}$. A este respecto,

42 Sánchez con Smith, C. S., 30 enero 2013, Rol No 1409-2012, cons. $9^{\circ}$ y $11^{\circ}$, LegalPublishing CL/ JUR/229/2013 (Primera Sala: redacción del ministro Guillermo Silva): "Los jueces, para dar estricto cumplimiento a lo dispuesto por el constituyente y el legislador, han debido ponderar toda la prueba rendida en autos, tanto aquella en que se sustenta la decisión, como la descartada o aquella que no logra producir la convicción del sentenciador en el establecimiento de los hechos, lo cual no se logra con la simple enunciación de tales elementos, sino que con una valoración racional y pormenorizada de los mismos".

43 Art. 768 N 5 CPC: "El recurso de casación en la forma ha de fundarse precisamente en alguna de las causas siguientes: 5 a. En haber sido pronunciada con omisión de cualquiera de los requisitos enumerados en el artículo 170"; Art. 170 N 4 CPC: "Las sentencias definitivas de primera o de única instancia y las de segunda que modifiquen o revoquen en su parte dispositiva las de otros tribunales, contendrán: Las consideraciones de hecho o de derecho que sirven de fundamento a la sentencia”.

44 Salamanca con Delgado y otra, C. S., 18 junio 2002, Rol No 2233-2001, cons. 6 ${ }^{\circ}$, Fallos del Mes $\mathrm{N}^{\circ} 500$ (Primera Sala: redacción del ministro Enrique Tapia). La Corte Suprema creyó que las afirmaciones del demandado en su contestación a una querella de restitución en un juicio seguido entre las mismas partes y previo al reivindicatorio, en donde negó el uso de la fuerza pero reconoció haber alterado los cercos y adentrado en el terreno de la actora, "involucran un reconocimiento o confesión espontánea de hechos personales, prestada en juicio diverso, pero seguido entre las mismas partes que actualmente litigan [...] constitutivo de un medio de prueba legal".

45 Romero con Garrido, C. S., 25 noviembre 2002, Rol No 4480-2001, cons. $3^{\circ}$, LegalPublishing CL/ JUR/429/2002 (Primera Sala: redacción del ministro Eleodoro Ortiz).

${ }^{46}$ Passalacqua con Covarrubias, C. S., 27 agosto 2003, Rol No 850-2002, cons. $1^{\circ}$ y $4^{\circ}$, Fallos del Mes $\mathrm{N}^{\circ} 513$ (Primera Sala: redacción del abogado integrante Enrique Barros).

${ }^{47}$ Polanco y otro con Saavedra y otros, C. S., 21 julio 2003, Rol No 2728-2002, cons. $1^{\circ}$, Fallos del Mes No 512, (Primera Sala: redacción del abogado integrante René Abeliuk).

${ }^{48}$ Aquí vale la pena recordar, por ejemplo, que hace seis décadas la Corte Suprema sostenía que "como la ley no ha señalado 'las reglas de la sana crítica', cualesquiera sean los reparos que pueda merecer la interpretación del mérito del dictamen pericial, ellos no serían constitutivos de errores legales o de derecho" (C. S., 26 marzo 1966, Revista de Derecho y Jurisprudencia, T. LXIII, sec. 1a, p. 375 citado en Rioseco, E., 
Alejandro Romero ha reconocido que hoy este control de los hechos es posible, debido a que "en nuestro sistema de casación en el fondo la apreciación de la prueba conforme a la sana crítica está pasando a ser concebida como una actividad que incide en el cómo se debe juzgar, y bajo tal premisa, que ella pueda configurar un error decisorio litis" ${ }^{9}$.

Como la ley exige que se trate de una infracción que haya "influido substancialmente en lo dispositivo de la sentencia” (art. 767 CPC), un control mediante la casación en el fondo en la valoración de la prueba se debería concentrar en la asignación de peso o "fuerza probatoria" que el juez le da a la información que valora ${ }^{50}$, algo que hasta la fecha la Corte Suprema ha preferido realizar mediante la casación en la forma ${ }^{51}$. El debate en torno a la posibilidad de este cambio de ruta en el control de la valoración -de la casación en la forma a la casación en el fondo- solo adquiere sentido una vez que se deja atrás la tesis de la soberanía judicial y se instala en su lugar la del control deferente del juicio de hecho.

\section{DE LA INCOMPETENCIA AL CONTROL DEFERENTE}

La reticencia a emplear el recurso de casación para que la Corte Suprema controle un fallo por motivos vinculados a los hechos se liga tanto a su modelo original, el francés, que le asignó una función puramente negativa -anular el fallo que infringe una declaración de la voluntad soberana, sin motivar la decisión y con un reenvío al juez de instancia- ${ }^{52}$, como en el español, que le asignó un rol jurisdiccional y fue el modelo seguido por la ley procesal chilena.

La prueba ante la jurisprudencia. Derecho civil y procesal civil, Editorial Jurídica de Chile, Santiago, 2002, $4^{\mathrm{a}}$ ed., T. I, p. 220), aunque ese discurso no era óbice para que el mismo tribunal -cuando así lo decidía- revisará la valoración de la prueba, incluso por la vía del recurso de queja, C. S., 19 diciembre 1962, Revista de Derecho y Jurisprudencia, T. XLIX, sec. $1^{\text {a }}$, p. 467 citado en Rioseco (n. 45), p. 251: “Al desentenderse el tribunal de alzada del mérito de los distintos informes periciales y aceptar como único antecedente para determinar el valor de los terrenos expropiados el señalado por la Dirección de I. Internos, incurre en una falta que procede enmendar por la vía de la queja, elevando la indemnización en consideración a aquellos otros informes periciales".

${ }^{49}$ Romero (n. 32), p. 113 (destacados en el original).

${ }^{50}$ En los términos de Alex Stein, "el peso probatorio debe comprenderse como una función de las razones que se dan en apoyo de los argumentos probatorios relevantes. Desbordando siempre el contenido asertivo de una sola fuente probatoria, tales razones descansan sobre numerosas fuentes de prueba, incluyendo la experiencia general. Estas razones son invariablemente 'ampliativas' en su naturaleza. Ellas siempre amplifican la información existente más que meramente reiterarla (en un sentido trivial o por enumeración estadística) y aplicarla deductivamente", Stein (n. 23), p. 255.

${ }^{51}$ Por ejemplo, la Corte Suprema ha resuelto que "procede casar de oficio por la causal del No 5 del art. 768 del Código de P. Civil en relación con el N 4 del art. 170 del mismo Código, la sentencia que basándose sustancialmente en el mérito que atribuye a informes periciales, se limita a hacer un resumen de ellos, sin formular consideraciones sobre su fuerza probatoria como lo ordena el art. 425 del Código de P. Civil”, C. S., 7 noviembre 1960, R.D.J., T. LVII, sec. $1^{\text {a }}$, p. 314 citada en Rioseco, cit. (n. 25), T. II, No 696, p. 380.

${ }^{52}$ Cortés, G., "Reflexiones sobre la evolución de la casación en el proceso civil”, en Revista de Derecho, Universidad de Concepción, N²11, 2002, pp. 166-167. 
Como se anticipó en un comienzo, el debate en torno al control de las decisiones judiciales respecto de los hechos y al contenido de las leyes reguladoras de la prueba ha estado ligado a -o eclipsado por- las discusiones acerca de los límites del recurso de casación. En este artículo se ha procurado escindir conceptualmente ambos temas y dirigir el análisis hacia el primer ámbito, para dar cuenta de la forma en que la Corte Suprema ha entendido -y entiende hoy- las leyes reguladoras de la prueba. A este respecto, la jurisprudencia de este siglo viene mostrando un abandono de la tesis de la incompetencia para controlar asuntos de hecho, abriendo paso a un control mínimo -vía casación por motivación defectuosa- que se aleja de la tesis tradicional de la soberanía judicial. Con todo, ese control mínimo aún carece de una explicación que dé cuenta de manera satisfactoria a preguntas como ¿qué dimensiones de la prueba deben controlarse?, ¿en qué casos? y ¿bajo qué parámetros? Enrique Paillás, por ejemplo, en su momento se limitó a decir que el control es mínimo o excepcional porque "la Corte de Casación no puede examinar nuevas pruebas ni tampoco reexaminar las pruebas que ha verificado el juez del fondo" 53 . Para configurar una mejor explicación a esta clase de preguntas es preciso abordar el tema desde la perspectiva que ofrece la tesis del control deferente.

Aquí el punto de partida es el siguiente: el modo en que se valora la prueba y se deciden los hechos en un proceso judicial es un asunto normativo; viene decidido directamente por la ley en algunas ocasiones (por ejemplo, mediante una presunción legal) o por medio de un reenvío legal a las reglas generales de la epistemología ${ }^{54}$. Ese ejercicio normativo, en tanto tal, en principio puede ser controlado por cualquiera de las Cortes, incluyendo a la Corte Suprema, la que se ha valido del deber judicial de motivar las sentencias y de la casación en la forma por motivación defectuosa para llevar adelante dicho control" ${ }^{55}$. En palabras de la Corte Suprema, "la fundamentación de las sentencias importa para las partes y el tribunal superior, quedar en posición de poder conocer, rebatir, impugnar y revisar, en su caso, las razones que formaron la convicción del juzgador, comprometiendo así aspectos de orden público que no es posible soslayar" 56 .

53 Paillás (n. 16), p. 99.

${ }^{54}$ Entre los motivos que justifican este vínculo entre el trabajo de los jueces y la racionalidad general en el modo de acceder al conocimiento se destaca, según Rodrigo Coloma y Claudio Agüero, el que "la sociedad reclama que el caso judicial se resuelva usando lo que se sabe en medicina, mecánica, antropología y psicología y que las razones que da el tribunal puedan ser transferidas a textos de historiografía, a una discusión política o a la noticia de un matutino, sin necesidad de hacer aclaraciones”, Coloma, R. y Agüero, C., "Lógica, ciencia y experiencia en la valoración de la prueba", en Revista Chilena de Derecho, Vol. 41, N 2, 2014 , p. 681.

${ }^{55}$ Como observó Carlos del Río, “mientras más racional sea la motivación-valoración, más posibilidades de articular controles eficaces sobre la corrección del juicio fáctico y jurídico, y, al contrario, mientras más orientada por la persuasión (subjetiva) y con valoración intimista e irracional, menos posibilidades de control, favoreciendo -en la práctica- modelos recursivos débiles o incluso ineficaces”, Del Río, C., "Tres apuntes sobre el recurso de nulidad y el enjuiciamiento fáctico a propósito de tres fallos de la Ilustrísima Corte de Apelaciones de La Serena”, en Revista de Derecho, Universidad Católica del Norte, 17, No 1, 2010, p. 135.

${ }^{56}$ Montes con Toloza, C. S., 4 octubre 2007, Rol N 3299-2007, cons. $7^{\circ}$ (Segunda Sala: redacción del ministro Raúl Ballesteros). 
En este sentido, el deber de motivar ayudó en un primer momento a la tarea de superar el uso de la libre valoración de la prueba como un "mantra" 57 y a refrendar la necesidad de cada juez de entregar razones que den cuenta de una justificación (= "sin piedras no hay puente" $)^{58}$. Pero aunque precisar si el juez ha dado "una reflexión que permita constatar la apreciación de cada uno de los medios probatorios" 59 sea una tarea ardua, pues, supone fijar "la frontera entre una motivación completa y adecuada y una insuficiente o defectuosa" ${ }^{60}$, el control deferente de las reglas de prueba no limita las posibilidades de la Corte Suprema a esta única hipótesis. La normatividad de las leyes reguladoras de la prueba, como un conjunto de deberes, obligaciones, permisos y prohibiciones, abre potencialmente su agenda de control hacia más supuestos que la motivación defectuosa. Ello invita a hacerse cargo de los dos principales riesgos que un control de este tipo puede suscitar.

\section{a. Formalismo y vulgarismo}

Los riesgos de extender el control de los hechos a la Corte Suprema han sido resumidos en el de formalismo -control restrictivo- y vulgarismo -control extensivo-. Para sortear ambos peligros es preciso contar con una adecuada noción de deferencia, capaz de lidiar incluso con un riesgo adicional en la práctica chilena: el auge constante de pretextos en el seno de la Corte Suprema para volver a instalar la tesis de la incompetencia. Entre estas excusas, además de las ya mencionadas, las que más se repiten son las de (i) la inmediación y oralidad del proceso judicial, y (ii) el carácter estricto del recurso de casación.

La primera de ellas puede neutralizarse recordando que lo que se controla son razones y no impresiones ${ }^{61}$, de modo que las reglas de inmediación y oralidad no son obstáculos para que la Corte Suprema evalúe el juicio de hecho, más aún si existe un registro de la prueba ${ }^{62}$. La justicia de familia es un buen ejemplo de la posibilidad de

${ }^{57}$ Maturana (n. 3), pp. 524, 526.

58 Accatino, D., "La arquitectura de la motivación de las premisas fácticas de las sentencias judiciales", en Hechos, evidencia y estándares de prueba. Ensayos de epistemología jurídica, Andrés Páez coordinador, Ediciones Uniandes, Bogotá, 2015, p. 83.

59 Guerrero con Meléndez, C. S., 11 julio 2007, Rol N 18-2006, cons. $3^{\circ}$ (Primera Sala: redacción de la ministra Margarita Herreros).

${ }^{60}$ Accatino, D., "Los peligros del cajón de sastre. Sentencia de nulidad por falta de fundamentación de las conclusiones probatorias en el caso Tocornal (Corte Suprema)", en Revista de Derecho, Universidad Austral, Vol. 20, N 1,2007 , p. 281.

${ }^{61}$ Esto no implica, necesariamente, llegar a la conclusión de Marcela Araya, en cuanto a que "debemos entonces desconfiar de lo emotivo, de lo íntimo, de las impresiones, pues aquellas no pueden explicarse racionalmente, son imposibles de justificar permaneciendo en la esfera de lo incontrolable”, Araya, M., Los hechos en el recurso de nulidad en materia penal, AbeledoPerrot, Santiago de Chile, 2011, p. 172. Las impresiones y las emociones pueden tener una racionalidad, pero de ello no se sigue que su control sea necesario para el trabajo judicial.

${ }^{62}$ Picó i Junoy, J., "Valoración de la prueba y segunda instancia civil: hacia la búsqueda del necesario equilibrio", en Revista Jurídica de Catalunya, No 3, 2009, pp. 683-689. 
ejercer este control en el marco de exigencias claras en cuanto a la motivación de la sentencia (art. 32 inciso $1^{\circ}$, Ley $\left.\mathrm{N}^{\circ} 19.968\right)^{63}$. Lo que sí puede discutirse es si la Corte Suprema tiene que dictar sentencia de reemplazo cuando casa el fallo o debe reenviar la tarea a un juez de instancia ${ }^{64}$.

El segundo pretexto es francamente inexplicable luego de las reformas en 1977 y 1995 a la casación, aunque vale la pena mencionarlo porque reapareció durante la implementación de la justicia penal, cuando la casación dio paso a la nulidad. En ese momento se intentó distinguir entre un control formal del razonamiento probatorio y otro sustancial o referido a la suficiencia de la prueba para cumplir con el estándar de prueba penal. La finalidad de esta distinción fue restringir el trabajo de las Cortes al primero de ellos diciendo que el recurso de nulidad era de derecho estricto ${ }^{65}$, lo que no es sino otra forma de decir que una Corte es incompetente para controlar los aspectos sustantivos del juicio de hecho, sin dar razones para ello.

\section{b. Deferencia}

El grado de control que la Corte Suprema ejerce sobre la aplicación de las reglas probatorias depende de un asunto que es normativo, no epistémico, y que se refiere a la deferencia que dicho tribunal le reconoce al juez de instancia. Un punto clave a este respecto es que un juez, cuando valora la prueba, le añade "algo más” a los datos que examina; ese "algo más” es fruto de una "reflexión” - esa es la imagen que ha dado la

${ }^{63}$ Para aludir solo a un caso: en Gallegos con Cabezas la Corte Suprema casó la sentencia de la Corte de Apelaciones de Arica que modificó "prudencialmente" la cuantía del fallo en primera instancia en cuanto a la compensación económica, sin dar razones para ello. La Corte Suprema sostuvo que "las motivaciones que dan los sentenciadores [de segunda instancia] constituyen solo una reiteración de las que consideró el sentenciador de la instancia, incurriendo los mismos en la omisión de dejar constancia de las consideraciones que han determinado su actuar, privando a las partes de conocer las razones en cuya virtud se ha resuelto del modo indicado", C. S., 13 diciembre 2010, Rol No 6460-2010, LegalPublishing N N $^{\circ} 7573$, cons. $3^{\circ}$ (redacción de la ministra Gabriela Pérez) citada en Larroucau, J., "La prueba del menoscabo en la justicia de familia”, en Estudios de Derecho Civil VIII, Carmen Domínguez, Joel González, Marcelo Barrientos y Juan Luis Goldenberg, coordinadores, Thomson Reuters, 2013, p. 90.

${ }^{64}$ Se ha dicho que si la infracción se relaciona con un medio de prueba en que la oralidad y la inmediación tienen un "papel relevante" (¿Qué cuenta como "papel relevante”?, ¿se refiere la prueba testimonial?), luego de anular el fallo debiera ordenarse una nueva audiencia de juicio o realizar la fase probatoria que corresponda, Rodríguez, C., "Límites del control de la valoración judicial de la prueba en el sistema de la sana crítica", en Justicia civil y comercial: Una reforma ¿cercana?, Francisco Leturia editor, Ediciones LYD, Santiago de Chile, 2011, p. 303. El Código Procesal Civil Modelo para Iberoamérica de 1989, en cambio, propuso lo siguiente: art. 247.3: "Si la casación se fundara en errónea decisión en cuanto a admisibilidad o valoración de la prueba, el Tribunal Supremo pronunciará sentencia sobre el fondo sobre la base de la prueba que juzgare admisible o la valoración que entendiere corresponder. Solo procederá el reenvío, si se estimare que la no admisión de prueba admisible afecta a la resolución sobre el mérito. En tal caso deberá procederse al diligenciamiento omitido y el posterior dictado de la sentencia que corresponda, por el Tribunal a quien se remita el proceso, conforme con lo dispuesto en el ordinal 2".

65 Accatino, D., "Forma y sustancia en el razonamiento probatorio. El alcance del control sobre la valoración de la prueba a través del recurso de nulidad penal”, Revista de Derecho, Pontificia Universidad Católica de Valparaíso, XXXII, 2009, pp. 349-356. 
propia Corte Suprema- que luego se hace pública en la motivación de la sentencia. Esto explica que la primera herramienta empleada para controlar estas decisiones haya sido la casación por motivación defectuosa, salvo que la propia ley lo impida, como ocurrió en 1918 en los juicios especiales (art. 768 inciso 2 CPC) ${ }^{66}$.

Ahora bien, sea cual sea el camino empleado por la Corte Suprema, lo que tiene relevancia en este punto es que el juez de instancia valora la prueba mediante cláusulas abiertas - gravedad, precisión y concordancia de una presunción; lógica, ciencia y experiencia en la sana crítica-, a cuya adecuada interpretación contribuye el diseño institucional de las instancias judiciales, especialmente de la primera y, en particular, cuando se trata de un juicio a base de audiencias. En ese caso el juez cuenta con un interrogatorio directo de los testigos, un examen de los expertos, filtros para admitir o rechazar la información, el debate de los abogados y otros elementos que lo dejan en una mejor posición para enfrentar casos complejos, en el entendido que un caso es complejo cuando las partes discrepan abiertamente acerca de los hechos, y según sea la cantidad y calidad de la prueba disponible.

La deferencia con el trabajo del juez de instancia descansa, luego, en que dicho marco institucional hace menos probable que se cometan errores en las decisiones relacionadas con la prueba. Pero como siempre hay un riesgo de error, la Corte Suprema necesita contar con las herramientas para corregirlos, o bien, con una justificación para desentenderse del tema (como ocurre, por ejemplo, en sede penal con las sentencias absolutorias en virtud del non bis in idem o double jeopardy). Como se ha dicho, la técnica más desarrollada hasta ahora es la que identifica las sentencias que contienen un razonamiento probatorio defectuoso, para anularlas ${ }^{67}$. Así, por ejemplo, sabemos que la motivación es defectuosa cuando el juez se limita a un análisis atómico de la prueba, olvidando su faceta holística ${ }^{68}$, ya que la valoración no solo admite una aproximación lineal, sino que también una reticular ( = en forma de red $)^{69}$. La deferencia en estos casos actúa exigiendo que esa omisión sea "de tal entidad que conlleva a la modificación de

${ }^{66}$ El Tribunal Constitucional ha declarado inaplicable por inconstitucional esta limitación en el juicio tributario y el de terminación del arrendamiento, Tribunal Constitucional, 2 enero 2015, Rol No 25292013-INA (redacción del ministro Iván Aróstica; voto en contra de los ministros Carlos Carmona, Marisol Peña, Francisco Fernández y Domingo Hernández) y Tribunal Constitucional, 4 junio 2015, Rol No 2677 2014- INA (redacción del ministro Iván Aróstica; voto en contra de los ministros Carlos Carmona, Marisol Peña, Gonzalo Pino y Domingo Hernández) analizados en Valenzuela, W., “¿Derecho a la casación? Lectura a contracorriente de la jurisprudencia del Tribunal Constitucional”, en Estudios Constitucionales, 13, $\mathrm{N}^{\circ} 2$, pp. 447 ss.

67 Accatino, D., "El modelo legal de justificación de los enunciados probatorios en las sentencias penales y su control a través del recurso de nulidad", en Formación y valoración de la prueba en el proceso penal, Daniela Accatino coordinadora, AbeledoPerrot, Santiago de Chile, 2010, p. 143.

${ }^{68}$ C. S., 30 noviembre 1955 , R.D.J., T. LII, sec. $1^{\text {a }}$, p. 388 citada en Rioseco, cit. (n. 25), T. II, N 774 , p. 421: "Procede casar de oficio la sentencia de alzada que examina separadamente los hechos probados, concluyendo que no produce cada uno prueba completa, siendo que el requisito de la concordancia de las presunciones obliga al examen conjunto de tales hechos, lo cual lleva a la conclusión de que, al existir entre ellos correspondencia o conformidad, constituyen fundamento para deducirlas".

${ }^{69}$ Accatino, D., “Atomismo y holismo en la justificación probatoria”, en Isonomía, No 40, 2014, pp. 38-40. 
la parte resolutiva de la sentencia o no puede ser ella reparada por otro medio"70. En este mismo sentido, marcamos como defectuoso un razonamiento en que la valoración de la prueba no incluye "el análisis de su pertinencia, oportunidad e importancia", ${ }^{71}$ contiene "consideraciones contradictorias que se destruyen recíprocamente" 72 o no dice "relación con los hechos básicos invocados por las partes, especialmente como extremos de sus acciones y excepciones" 73 .

El siguiente paso, como se advertía en la segunda parte, es dar con una técnica similar fuera de estas variantes de la hipótesis de la motivación defectuosa que permita diferenciar los escenarios en que el juez aplica incorrectamente las leyes reguladoras de la prueba, distinguiendo, por ejemplo, los casos de inadmisibilidad de una prueba (por ilícita o por irrelevante), de la elección inadecuada entre dos o más evidencias contradictorias, o bien, de la incorrecta aplicación de un estándar de prueba. Solo una vez que dichas hipótesis son identificadas es posible modular el nivel de deferencia que la Corte Suprema le debe a las decisiones del juez de instancia en cada supuesto.

\section{CONCLUSIONES}

Leyes reguladoras de la prueba es el nombre usado por la jurisprudencia chilena para dar cuenta del estatuto probatorio que rige las decisiones del juez respecto de los hechos. Las conclusiones de este trabajo acerca de cómo la Corte Suprema ha entendido dicha categoría son las siguientes:

1. La tesis clásica de la soberanía judicial interpretó a las leyes reguladoras como un asunto de prudencia del juez. Esta tesis ha admitido dos lecturas: (i) una aproximación fuerte, en donde las leyes reguladoras son simples consejos y (ii) un enfoque débil (mayoritario en la jurisprudencia), que reconoce en ellas un conjunto de deberes, obligaciones, limitaciones y prohibiciones que el juez debe respetar cuando toma su decisión.

2. En cuanto a la valoración de la prueba, en particular, la Corte Suprema reconoce a veces, y en otras niega, que la valoración forme parte de estas leyes reguladoras. En el primer caso, asume que las reglas que "disciplinan la forma como el sentenciador debe realizar la ponderación comparativa” de las pruebas son leyes reguladoras, lo que abre la posibilidad de controlar su aplicación incluso mediante la casación en el fondo.

\footnotetext{
${ }^{70}$ Mosquera y Maturana (n. 28), p. 250.

${ }^{71}$ C. S., 1 agosto 1928 , Revista de Derecho y Jurisprudencia, T. XXVI, sec. $1^{\text {a }}$, p. 426 citado en Rioseco (n. 41), p. 209

${ }^{72}$ C. S., 20 junio 1978, Revista de Derecho y Jurisprudencia, T. LXXV, sec. $1^{\text {a }}$, p. 203 citado en Rioseco (n. 41), p. 217.

${ }^{73}$ C. S., 1 octubre 1980, Revista de Derecho y Jurisprudencia, T. LXXVII, sec. $1^{\text {a }}$, p. 141 citado en Rioseco (n. 41), p. 210.
} 
3. Dicho control fue esporádico durante buena parte del siglo XX en lo relativo a la valoración de la prueba, pues la Corte Suprema se consideró un tribunal incompetente para llevarlo a cabo. A estos efectos, el mismo tribunal elaboró varias excusas específicas -la subjetividad de quien valora, la distinción entre hecho y derecho, la distinción entre reglas ordenatoria litis y decisoria litis-, siendo la más interesante de ellas la que entiende a las leyes reguladoras de la prueba como un conjunto de normas imperativas. Más adelante han surgido otros pretextos (oralidad e inmediación, recurso de derecho estricto) que buscan volver a la tesis de la incompetencia, pero ninguno de ellos ha resultado concluyente.

4. La jurisprudencia que se ha dictado en temas centrales como la filiación (gravedad de una presunción) y las acciones reales (valoración del peritaje según la sana crítica) pone de manifiesto que la aplicación judicial de las reglas de prueba -incluso de aquellas que son potestativas- puede ser controlada por la Corte Suprema, ya sea por mandato legal o por decisión de la misma Corte.

5. Para transitar desde la tesis de la soberanía judicial hacia un control deferente de las leyes reguladoras es preciso delimitar las dimensiones normativas de la prueba que deben ser controladas, evitando la tendencia a barrer todos los supuestos de infracción del estatuto probatorio -vía casación en la forma- bajo la alfombra de la motivación defectuosa.

6. La deferencia con el juez de instancia se justifica principalmente porque dicho juez valora la prueba mediante cláusulas abiertas a cuya correcta interpretación contribuye el contexto institucional de las instancias, en especial de la primera cuando se trata de un juicio basado en audiencias.

7. Las reglas que configuran este control deferente de la Corte Suprema distribuyen riesgos de error judicial en el campo de los hechos, reduciendo al mismo tiempo el peligro del formalismo (control mínimo) y el del vulgarismo (control excesivo). Por ese motivo debería tratarse de normas legales, más que judiciales.

\section{BIBLIOGRAFÍA}

Accatino, D., "La arquitectura de la motivación de las premisas fácticas de las sentencias judiciales”, en Hechos, evidencia y estándares de prueba. Ensayos de epistemología jurídica, Andrés Páez coordinador, Ediciones Uniandes, Bogotá, 2015, pp. 65-87.

Accatino, D., “Atomismo y holismo en la justificación probatoria”, en Isonomía, No 40, 2014, pp. 17-59.

AcCatino, D., "El modelo legal de justificación de los enunciados probatorios en las sentencias penales y su control a través del recurso de nulidad", en Formación y valoración de la prueba en el proceso penal, Daniela Accatino coordinadora, AbeledoPerrot, Santiago de Chile, 2010 , pp. 119-143.

Accatino, D., "Forma y sustancia en el razonamiento probatorio. El alcance del control sobre la valoración de la prueba a través del recurso de nulidad penal", Revista de Derecho, Pontificia Universidad Católica de Valparaíso, XXXII, 2009, pp. 347-362. 
AcCatino, D., "Los peligros del cajón de sastre. Sentencia de nulidad por falta de fundamentación de las conclusiones probatorias en el caso Tocornal (Corte Suprema)", en Revista de Derecho, Universidad Austral, Vol. 20, N 1, 2007, pp. 273-287.

Allen, R. y Pardo, M., "The Myth of the Law-Fact Distinction”, en Northwestern University Law Review, Vol. 97, No 4, 2003, pp. 1769-1807.

Anabalón, C., El juicio ordinario de mayor cuantía, Editorial Jurídica de Chile, Santiago, 1954, 617 pp.

Araya, M., Los hechos en el recurso de nulidad en materia penal, AbeledoPerrot, Santiago de Chile, 2011, 209 pp.

Atria, F., "Proceso civil”, en Revista de Derecho, Universidad Adolfo Ibáñez, No 2, 2004, pp. 249-353.

Bohlen, F., "The Effect of Rebuttable Presumptions of Law upon the Burden of Proof", en University of Pennsylvania Law Review and American Law Register, Vol. 68, No 4, 1920, pp. 307-321.

Coloma, R. y Agüero, C., "Lógica, ciencia y experiencia en la valoración de la prueba", en Revista Chilena de Derecho, Vol. 41, No 2, 2014, pp. 673-703.

Correa, C., "La presunción de hecho como figura jurídica en el derecho procesal civil alemán", en Revista de Estudios de la Justicia, No 20, 2014, pp. 115-170.

Cortés, G., "Reflexiones sobre la evolución de la casación en el proceso civil", en Revista de Derecho, Universidad de Concepción, No 211, 2002, pp. 165-178.

DAmašKa, M., Las caras de la justicia y el poder del Estado. Análisis comparado del proceso legal, traducción de Andrea Morales, Editorial Jurídica de Chile, Santiago, 2000 (1986), 430 pp.

Del Río, C., "Motivo de casación en el fondo civil en Chile: Problemas y perspectivas de reforma", en Ius et Praxis, Universidad de Talca, Vol. 21, No 2, 2015, pp. 161-198.

Del Río, C., "Tres apuntes sobre el recurso de nulidad y el enjuiciamiento fáctico a propósito de tres fallos de la Ilustrísima Corte de Apelaciones de La Serena", en Revista de Derecho, Universidad Católica del Norte, 17, Nº 1, 2010, pp. 131-146.

Ho, H. L., A Philosophy of Evidence Law. Justice in the Search for Truth, Oxford Monographs on Criminal Law, Oxford University Press, 2008, 300 pp.

Hunter, I., La aplicación judicial del derecho en el proceso civil. Doctrina, jurisprudencia y derecho comparado, Thomson Reuters, Santiago de Chile, 2015, 217 pp.

Hunter, I., "Control judicial de las reglas de la sana crítica (Corte Suprema)", en Revista de Derecho, Universidad Austral, Vol. 24, No 1, 2012, pp. 243-251.

Larroucau, J., “Acciones reales y estándares de prueba”, en Ius et Praxis, Universidad de Talca, Vol. 21, No 2, 2015, pp. 109-160.

Larroucau, J., “¿Cómo se prueba la responsabilidad civil médica en la justicia chilena?”, en Revista de Derecho, Universidad Austral, Vol. 27, No 2, 2014, pp. 43-79.

Larroucau, J., "Presunciones, negativa (in)justificada y prueba de ADN en la filiación", en Revista de Derecho de Familia, Santiago de Chile, No 4, 2014, pp. 21-49.

Larroucau, J., "La prueba del menoscabo en la justicia de familia", en Estudios de Derecho Civil VIII, Carmen Domínguez, Joel González, Marcelo Barrientos y Juan Luis Goldenberg coordinadores, Thomson Reuters, 2013, pp. 73-91.

López, C., "Apreciación de la prueba por la sana crítica y procedencia del recurso de casación en el fondo en los procesos ante los tribunales de familia”, en Gaceta Jurídica, No 294, 2004, pp. 22-27.

Marín, J. C., "Proceso civil", en Revista de Derecho de la Universidad Adolfo Ibáñez, No 4, 2016, pp. 315-397.

MARín, J. C., "Proceso civil. Los orígenes de la casación nacional. La casación en la jurisprudencia de 2005”, en Revista de Derecho de la Universidad Adolfo Ibáñez, No 3, 2013, pp. 165-235. 
Maturana, J., Sana crítica. Un sistema de valoración racional de la prueba, Thomson Reuters, Santiago de Chile, 2014, 616 pp.

Mosquera, M. y Maturana, C., Los recursos procesales, Editorial Jurídica de Chile, Santiago, 2010, $613 \mathrm{pp}$.

Muñoz, S., "Presente y futuro de la casación civil en Chile”, en Derecho procesal contemporáneo. Ponencias de las XXII Jornadas Iberoamericanas de Derecho procesal, Raúl Tavolari coordinador, Editorial Jurídica de Chile, Santiago, T. I, 2010, pp. 90-182.

Paillás, E., El recurso de casación en materia civil. Derecho chileno y comparado, Editorial Jurídica de Chile, Santiago, 2008, 182 pp.

Paillás, E., Estudios de derecho probatorio, Editorial Jurídica de Chile, Santiago, $2^{a}$ ed. actualizada, 2002, 159 pp.

Peñailillo, D., La prueba en materia sustantiva civil. Parte general, Editorial Jurídica de Chile, Santiago, 1989, 126 pp.

Picó i JunOY, J., "Valoración de la prueba y segunda instancia civil: hacia la búsqueda del necesario equilibrio", en Revista Jurídica de Catalunya, No 3, 2009, pp. 680-692.

Rioseco, E., La prueba ante la jurisprudencia. Derecho civil y procesal civil, Editorial Jurídica de Chile, Santiago, 2002, 4a ed., T. I, 493 pp.

Rioseco, E., La prueba ante la jurisprudencia. Derecho civil y procesal civil, Editorial Jurídica de

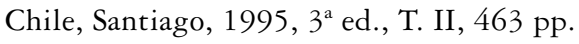

Rodríguez, C., "Límites del control de la valoración judicial de la prueba en el sistema de la sana crítica”, en Justicia civil y comercial: Una reforma ¿cercana?, Francisco Leturia editor, Ediciones LYD, Santiago de Chile, 2011, pp. 271-305.

Romero, A., El recurso de casación en el fondo civil. Propuestas para la generación de precedentes judiciales, Thomson Reuters, Santiago de Chile, 2013, 225 pp.

Romero, A., "La discriminación judicial como nuevo error decisorio litis en el proceso chileno", en Revista Chilena de Derecho, Pontificia Universidad Católica, Vol. 38, No 2, 2011, pp. 339-348.

Romero, A., Aguirrezabal, M. y Baraona, J., "Revisión crítica de la causal fundante del recurso de casación en el fondo en materia civil”, en Ius et Praxis, Vol. 14, N 1, 2008, pp. 225-259.

SAlgado, L., La prueba: Objeto, carga y apreciación. Comentarios de jurisprudencia, Editorial Jurídica de Chile, Santiago, 1979, 146 pp.

Stein, A., "Contra la 'prueba libre”", traducción de Jorge Larroucau, Revista de Derecho de la Universidad Austral, Vol. 26, N², 2013 (1997), pp. 245-261.

STEIN, A., "The Refoundation of Evidence Law", Canadian Journal of Law E Jurisprudence, 1996, Vol. 9, pp. 279-342.

TAruffo, M., El vértice ambiguo. Ensayos sobre la Casación civil, traducción de Juan Monroy Palacios y Juan Monroy Gálvez, Palestra Editores, Lima, 2005 (1991), 278 pp.

VAlenzuela, W., “¿Derecho a la casación? Lectura a contracorriente de la jurisprudencia del Tribunal Constitucional", en Estudios Constitucionales, 13, No 2, pp. 447-472.

Zavala, J., Jurisprudencia del recurso de casación en el fondo y en la forma, Editorial PuntoLex, Santiago de Chile, 2007, 425 pp. 
